\title{
Technoeconomic Assessment of Beetle Kill Biomass Co-firing in Existing Coal Fired Power Plants in the Western United States
}

\author{
E. Beagle and E. Belmont* \\ University of Wyoming, Department of Mechanical Engineering, 1000 E. University \\ Ave., Laramie, WY, USA, 82071 \\ *Corresponding author: ebelmont@uwyo.edu
}

\begin{abstract}
Widespread mortality of forests in the western United States due to a bark beetle epidemic provides a source of biomass for power generation. This study assessed availability and economics of co-firing beetle kill biomass with coal in power plants in the western U.S. Since biomass may be considered carbon neutral under careful management, co-combustion of biomass with coal provides power plants a way to meet emission reduction requirements, such as those in the EPA Clean Power Plan (CPP). Cost has been a barrier to co-firing, but the economics are altered by emission reduction requirements, such as CPP guidelines. The present study assessed beetle kill biomass availability in national forests in Wyoming and Colorado through Geographic Information System (GIS) analysis of U.S. Forest Service (USFS) data. Power plants near beetle kill mortality were identified as candidates for co-firing. An economic assessment of costs to implement co-firing was conducted. Co-firing reduces the need for the USFS to manage beetle kill trees
\end{abstract}


when they are harvested for energy use, and these mitigated treatment costs were considered as an effective subsidy of co-firing. The results of this analysis include beetle kill availability, costs, and annual $\mathrm{CO}_{2}$ emissions reductions that can be met by co-firing.

Keywords: beetle kill; biomass; co-firing; EPA Clean Power Plan; greenhouse gases

\section{Introduction}

Research and deployment of renewable energy sources are increasing due to several major drivers, including the needs for energy independence and security, renewable energy alternatives to fossil fuels, and decrease in greenhouse gas emissions. Biomass is an abundant resource (Goerndt et al., 2013; Prestemon et al. 2013) and may be considered a low-carbon or carbon neutral and sustainable energy source with careful planning and management, making it attractive for renewable energy applications (Sami et al., 2001; Reijnders, 2006). The question of how to account for biogenic emissions in the United States is still under debate. In November 2014, the EPA released an updated Framework for Assessing Biogenic $\mathrm{CO}_{2}$ Emissions from Stationary Sources which takes into account scientific and technical studies to assess carbon emissions from biogenic sources (Climate Change Division, 2014). This framework is not yet finalized, making accurate and reliable accounting of biogenic emissions for policy compliance difficult. Nonetheless, assessment of potential emission reductions from bioenergy applications is important and can help inform policy making.

Biomass can be utilized in a variety of energy conversion methods. These include combustion, where biomass can be burned alone or co-combusted with 
other fuels such as coal, conversion to liquid fuels through pyrolysis, and conversion to gases through gasification (Eriksson et al. 2007). Co-combustion of biomass with coal, also called co-firing, is the most viable of these options in the near term because combustion technology is mature and can utilize existing power plant infrastructure (Hughes 2000; Tharakan et al. 2005). Commercial scale biomass pyrolysis and gasification are being investigated but are currently limited (Kayhanian et al., 2007; Escudero et al., 2013). Firing biomass alone in a power plant is technologically feasible, but it is currently often cost prohibitive to build the new plants and equipment that would be required to accommodate pure biomass combustion (Hein and Bemtgen, 1998).

Although biomass co-firing with coal is currently the least expensive biomass energy technology, it is generally not economically competitive with power generation from fossil fuels alone in the U.S. Economic subsidies and environmental policies can, however, provide additional incentives for utilizing the biomass resource potential in the United States. Of particular interest is the Environmental Protection Agency Clean Power Plan (EPA CPP), which calls for a reduction in $\mathrm{CO}_{2}$ emissions to $68 \%$ of 2005 emission levels from electric power generators by 2030 (EPA, 2015a). Other incentives that have been proposed and are particularly relevant to the western United States include subsidies and grants from the U.S. Forest Service (USFS) for utilization of beetle kill biomass in energy applications (USFS, 2014). The USFS has recognized the potential for beetle kill biomass use in energy applications and has committed funding and grants to incentivize these 
programs. These incentives have the potential to significantly change the economics of utilizing biomass for energy applications.

This study examines the technical viability and economics of co-firing wood from bark beetle-killed trees, which are abundantly available and negatively affecting forests in the western United States, in existing coal fired power plants. Results are examined in the context of the EPA CPP emission reduction guidelines. Additional benefits of utilizing beetle-killed wood include a reduced burden on the USFS to treat the affected forests; the economic benefit of this is considered in the form of a subsidy to co-firing plants in this study. While co-firing of various types of biomass is currently implemented across the United States and internationally, particularly in the European Union, beetle-killed trees are not currently used as a biomass source for co-firing in the United States. Additionally, the co-firing plants that are currently operating in the United States are not co-located with the abundant supply of beetle-killed wood; thus, this study evaluates the feasibility of utilizing a novel source of biomass for power plants that are not currently taking advantage of co-firing as an emissions reduction strategy. First, the amount of available beetle kill biomass is assessed considering distance to existing coal fired power plants and the amount of biomass required to meet co-firing needs. Second, an economic assessment is used to calculate the cumulative costs as well as cost per $\mathrm{Mg}$ of $\mathrm{CO}_{2}$ reduced for each power plant under two scenarios. In the first scenario, the co-firing energy fraction, or level, that would permit the utilization of all beetlekilled wood within a $160 \mathrm{~km}$ radius of the plant over 20 years is determined. In the second scenario, a fixed co-firing energy fraction of 0.20 , or a $20 \%$ co-firing level, is 
implemented. The years possible to co-fire at this level given the beetle kill biomass availability near the plant are determined. Economics are presented for both scenarios, and the impact of a subsidy based upon mitigated USFS beetle treatment burden is considered. Emission reductions mandated by the EPA CPP and achieved through the two co-firing scenarios are determined, as well as the fraction of total beetle-affected forests utilized in each scenario.

\section{Background}

\subsection{Bark Beetle Epidemic}

There are over 20 species of bark beetle, including Dendroctonus ponderosae (mountain pine beetle), that are a natural presence in United States forests. Populations of these insects have risen to unprecedented levels since 1996, causing high levels of tree mortality. Droughts, rising winter temperatures, and homogeneous tree stand distributions are the major contributors to this epidemic (USFS, 2011b). Estimates indicate that over half a billion cubic meters of standing dead timber could potentially be salvaged from across the western United States (USFS, 2011b). The areas most heavily affected include northern Colorado, Southern Wyoming, Western Montana and Idaho.

The high level of tree mortality in forests, particularly in the western United States, is problematic for several reasons. The USFS estimates that 100,000 beetle kill trees fall daily in Northern Colorado and Southern Wyoming alone (USFS, 2011b). Falling trees pose a significant safety risk for people, can damage local infrastructure and waterways, and can block roads needed for emergency vehicles or other uses (USFS, 2011b). As a result of these safety risks and concerns, 
management of the beetle kill epidemic has become a top priority for the USFS (USFS, 2011b).

Given that the dead trees from this epidemic represent, at best, a waste management problem and, at worst, a significant threat to human and forest health, the benefits of utilizing this biomass source for bioenergy is gaining recognition (Jeffers et al., 2013). The USFS has recognized the potential for bioenergy from this beetle kill wood. In its 2011 Western Bark Beetle Strategy report (USFS, 2011b), the USFS established specific objectives related to the development of bioenergy projects that utilize beetle kill biomass as a feedstock. These objectives include utilization of material removed from beetle-killed forests to benefit local communities through job creation and potentially decrease the cost of forest treatment, and provision of grants and other forms of assistance to encourage cofiring of coal and wood at existing plants. Wyoming Governor Matt Mead, in his energy strategy entitled Leading the Charge, also included an objective related to the utilization of beetle kill wood for energy applications: Objective 3C states that recommendations will be considered for using beetle-killed timber in energy production (Governor Mead, 2013).

Alternative utilization pathways for beetle kill biomass include its use as timber, but this is often not economically viable in the western United States and trees lose integrity for timber use as they decompose (Prestemon et al., 2013). As a result, bioenergy is one of the most attractive longer-term uses of this resource. Furthermore, without proper management and use, dead trees remain in the forest to decompose or burn in wildfires; while the interaction between insect infestation 
and wildfire intensity is complex (Meigs et al., 2016), destruction of beetle-kill trees through any means releases the carbon content of those trees in the form of greenhouse gases. Therefore, utilizing beetle-killed biomass in energy applications allows for the potential net decrease of emissions from the power generation sector by displacing fossil fuels (Galik et al., 2015).

\subsection{Biomass Co-firing}

Co-firing biomass with coal in existing coal-fired power plants is an attractive option for biomass utilization because it is the lowest cost near term means of reducing $\mathrm{CO}_{2}$ emissions from electricity generation (Tharakan et al., 2005). A dedicated biomass-fired power plant achieves conversion efficiencies around $25 \%$, while biomass co-fired with coal achieves efficiencies of 33-37 \% (Hansson et al., 2009; Sahu et al., 2014). Biomass co-firing can also decrease emissions of pollutants such as $\mathrm{NO}_{\mathrm{x}}$ and $\mathrm{SO}_{\mathrm{x}}$ (Hansson et al., 2009). In addition to higher efficiencies and reduced emissions, co-firing can utilize existing infrastructure and is a relatively well-developed technology. However, there are several major technical challenges to the widespread implementation of biomass co-firing, including fuel preparation, transportation and storage, ash deposition, pollutant formation, corrosion, fly ash utilization, and fuel conversion efficiency (Baxter, 2005), making a 20\% energy fraction of biomass feasible with current technology (Sahu et al., 2014; Hansson et al., 2009; Hughes, 2000).

\section{3. $\quad$ EPA Clean Power Plan}

In August 2015, the EPA released its finalized CPP guidelines, which aim to reduce $\mathrm{CO}_{2}$ emissions from electricity generation in the United States to $68 \%$ of 
2005 emission levels by 2030 (EPA, 2015a). Though the implementation of the CPP continues to face contentious debate, the CPP rule provides the best current basis for analysis of $\mathrm{CO}_{2}$ regulations in the United States. The rule gives each state the flexibility to develop individual plans, and the EPA has proposed three major building blocks for states to use to decrease emissions. These building blocks are: efficiency improvements in existing coal fired power plants, increased numbers of natural gas combined cycle plants, and increased deployment of renewable and low carbon energy technologies (Wilkerson et al., 2014; EPA 2015d). Existing coal fired power plants therefore essentially have three options to meet the required emission reductions: improve efficiency, install carbon capture and storage technologies, and/or deploy renewable and low carbon energy technologies, such as biomass cofiring.

\section{Methods}

An economic model was developed to determine the cost to implement beetle kill biomass co-firing in existing coal-fired power plants in the western United States. Two scenarios were analyzed for five power plants in the region. Four of these plants are in Colorado and one is in Wyoming. These plants were selected based upon nearby beetle kill availability. In the first scenario (Scenario 1), the fraction of feedstock energy currently provided by coal that would need to be replaced by biomass, or co-firing level required, to use all available beetle kill biomass within a $160 \mathrm{~km}$ radius of the plant over 20 years was determined. An economic assessment was used to calculate the effective cost per $\mathrm{Mg}$ of $\mathrm{CO}_{2}$ mitigated based upon capital and operating costs to co-fire biomass in each power 
plant. In the second scenario (Scenario 2), the co-firing level in each plant was fixed at an energy level of $20 \%$ as this is representative of co-firing levels achievable and in use at existing facilities (Hansson et al., 2009). The years possible to co-fire at this level based upon beetle kill availability were examined and the cost of $\mathrm{CO}_{2}$ mitigation was calculated. Assuming the combustion of beetle kill biomass to be carbon neutral (Baxter, 2005; Gan and Smith, 2006), the fraction of emission reductions required by the CPP that were met by co-firing was determined for both states and both scenarios. Additionally, current USFS beetle kill management funding was used to determine the impact of a novel subsidy on co-firing economics.

\subsection{Power Plants for Co-firing}

Plants of interest for this study were selected based on the following criteria:

- Located in USFS Region 1 (Idaho, Montana and North Dakota) or Region 2 (Wyoming, Colorado, South Dakota and Nebraska): States of interest were limited to USFS Regions 1 and 2 because the most extensive beetle kill mortality in the United States is found in that area.

- Less than 40 years of operation (built after 1974): Plants with less than 40 years of operation were selected in order to analyze plants with at least 20 years of operation remaining.

- Within $160 \mathrm{~km}$ of National Forests with beetle-kill tree mortality: Transportation distance contributes significantly to the total cost of biomass utilization in energy applications (Liu et al., 2014). Other studies suggest that biomass transportation distances of approximately $100 \mathrm{~km}$ are economically feasible (Goerndt et al., 2013). In order to 
comprehensively evaluate economic feasibility of co-firing, and given the inclusion of a subsidy in this study to offset additional costs of co-firing and encourage management and utilization of beetle kill biomass, the maximum transportation distance of $160 \mathrm{~km}$ was chosen.

After identifying power plants in the region that meet the above criteria, the following nine power plants remained: Arapahoe (CO), Cherokee (CO), Comanche (CO), FMC and General Chemical (WY), Hardin Generator Project (MT), Jim Bridger (WY), Laramie River Station (WY), Martin Drake (CO), and Rawhide (CO). While Martin Drake is currently co-firing coal with wood and wood wastes, this study examines Martin Drake as a viable candidate for beetle kill biomass co-firing. Of these nine plants, only five were found to have sufficient beetle kill biomass within the specified $160 \mathrm{~km}$ radius to make co-firing feasible. These five plants were Arapahoe (CO), Cherokee (CO), Martin Drake (CO), Rawhide (CO) and FMC and General Chemical (WY). Specifications of these five plants are given in Table 1. The four plants eliminated did not have enough beetle kill biomass within the entire 160 $\mathrm{km}$ radius to meet the fuel requirements for a $20 \%$ co-firing level for a single year.

Table 1. Selected plant characteristics

\subsection{Beetle Kill Biomass Availability}

The amount of beetle kill biomass near power plants and available for cofiring in the western U.S. was determined by analysis of the USFS Insect and Disease Western Bark Beetle Survey, which provided geographic data of National Forest land with high levels of mortality due to bark beetles (USFS, 2011a). Expansion of beetle mortality has been shown to be slowing, which is thought to be due to depletion of 
host trees in affected areas (Meddens and Hicke, 2014). While some dynamic change is anticipated due to slow expansion and consumption by wildfire, the assumption of steady supply is expected to be a reasonable estimate of beetle-killed wood available over the time frame of the study (Jenkins et al., 2008). The data were implemented in GIS software ArcGIS along with the locations of coal-fired power plants in the region. GIS maps were then analyzed using ImageJ (Rasband, 2014) software to determine the area, in $\mathrm{km}^{2}$, of beetle kill trees within a $160 \mathrm{~km}$ radius of each power plant. A density conversion of $4.94 \mathrm{Gg} \mathrm{km}^{-2}$ (on a dry basis) was applied to determine beetle kill biomass availability on a weight basis. This conversion is based upon a beetle kill biomass supply simulation done by Mobini et al. (2011) that takes into account harvesting considerations such as availability, weather variation and terrain conditions in the forested areas.

In order to account for heterogeneous biomass distributions around each of the plants, biomass availability as a function of distance from each plant was determined. Affected area with increasing radial distance from each plant was calculated. This data was fit with a $4^{\text {th }}$ order polynomial to determine beetle kill biomass availability as a function of distance from each plant. These results were used to calculate the variable transportation distance and associated costs in the economic model.

\subsection{Policy Considerations}

\subsubsection{EPA Clean Power Plan}

The model developed in this study determines the costs that would be incurred by existing coal fired power plants if biomass co-firing were implemented 
to reduce plant emissions. While the EPA CPP mandates a reduction in emissions nationwide by $32 \%$ of 2005 emission levels by 2030 , each state has individual targets that may be greater or less than $32 \%$. For example, Wyoming has required emission reductions of $44.3 \%$ while Colorado has required emission reductions of $40.5 \%$ (EPA, 2015a-c).

Two different co-firing scenarios were evaluated for each of the power plants analyzed in this study. In Scenario 1, the co-firing levels were determined such that all beetle kill biomass available to the plants within a $160 \mathrm{~km}$ radius of each was used in 20 years. In Scenario 2, the energy co-firing level was set to $20 \%$ and the years possible to co-fire based on beetle kill biomass availability were determined. Total state emission reductions for both scenarios were compared to the emission reductions required by the EPA CPP. An estimated cost per $\mathrm{Mg}_{\text {of }} \mathrm{CO}_{2}$ eliminated by co-firing was calculated for both of these scenarios. These costs are additional costs to the plants in addition to current operating costs.

\subsubsection{USFS Subsidy}

A novel subsidy (or "USFS subsidy") based upon mitigated USFS expenses for beetle-kill treatment was proposed and considered in this study, and the extent to which this incentive could offset the cost to implement co-firing was determined. The subsidy is a novel policy option based upon current USFS expenditure and grants. The USFS currently offers a number of grant programs to energy companies that utilize beetle kill biomass. Two examples include the Statewide Wood Energy Teams Cooperative Agreement and the Wood to Energy Grant. These grants award up to $250,000 \$$ to selected awardees for projects that utilize woody biomass from 
National Forest Lands for energy production (USFS, 2014). However, these grants are a single value, onetime payment. In this study, an annual subsidy was calculated by dividing the total funding in the Region 2 USFS budget allocated to beetle kill management by the number of square kilometers the USFS planned to treat in Region 2 in 2011 (USFS, 2011b). This value was determined to be 219,000 \$ (sq $\mathrm{km})^{-1}$ and was then incorporated into the economic model as an annual subsidy payment to power plants based on the number of square kilometers of biomass that the power plant would use for co-firing; the power plant would effectively be helping the USFS in managing the beetle killed forest by removing material that it uses for co-firing. In this way, the funds utilized in USFS beetle-kill management functions would be used to offset power plant costs of beetle-kill biomass co-firing, while ensuring that the USFS goals of beetle-kill management are achieved. This subsidy framework is not currently in use by the USFS, and is introduced in this study to determine the impact that such a subsidy could have on offsetting costs for plants that implement co-firing. The USFS budget was used to determine the size of this subsidy since the available funding has already been allocated specifically for beetle kill management.

\subsection{Economic Assessment}

An assessment of the economics of co-firing as a path to achieving emission reduction requirements, such as those of the EPA CPP, was conducted. The assessment model was applied to each power plant in this study. The economics for co-firing in all five plants were considered under the two scenarios, and with and without the USFS subsidy. 
Costs associated with biomass co-firing in existing coal-fired power plants and incorporated into the economic model include capital, operation and maintenance, transportation, harvesting, and chipping costs. Capital costs were imposed on a onetime basis, while all other costs were incurred annually. Capital costs include construction of storage, grinding, and feeding facilities for biomass (Hughes, 2000). Transportation costs were broken down into fixed and variable costs, where the latter changed each year as a function of distance from the plant to the biomass source. This transportation distance was determined using the biomass availability distribution curves found in the beetle kill availability portion of the study. The economics model was implemented in Excel. Table 2 is a summary of costs used in the model.

Table 2. Summary of economic model input values

Financial benefits to the plant include fuel costs saved by replacing coal with biomass. The cost of coal was calculated from projections through 2030 (John T. Boyd Company, 2011). The USFS subsidy proposed in this study would provide additional financial benefit to co-firing plants if implemented. Without the USFS subsidy, annual additional costs to the plant are calculated by:

$$
A O C_{i}=F C S_{i}-\left(O M+V T_{i}+F T+H+C\right)
$$

With the inclusion of the subsidy this equation becomes:

$$
A O C_{i}=F C S_{i}+F S-\left(O M+V T_{i}+F T+H+C\right)
$$

Where AOC is the additional operating costs to the plant $\left(\$ \mathrm{yr}^{-1}\right), \mathrm{FCS}$ are the fuel costs saved by replacing a certain amount of coal with biomass, FS is the USFS subsidy, OM are operation and maintenance costs, VT are the variable 
transportation costs, FT are the fixed transportation costs, $\mathrm{H}$ are the harvesting costs and $\mathrm{C}$ are the chipping costs. For the model, FS, OM, FT, H and C are based only on plant size and biomass needed so they are the same every year. FCS, VT and AOC depend upon the price of coal and transportation distance respectively, which change on an annual basis and thus these values change annually. The subscript $i$ indicates the year of consideration.

For both scenarios and all five plants, annual and cumulative costs were determined with and without the inclusion of the USFS subsidy. All costs were converted into present value (2016) dollars using a discount rate of $4 \%$ (Row et al., 1981; Moore et al. 2004).

Present value of costs is estimated by

$$
C_{P V}=\frac{\sum C_{a}}{(1+d)^{t}}
$$

where $C_{P V}$ is the net present value of total cost, $C_{a}$ is the annual cost to the plant, including the transportation, harvesting, chipping and operation and maintenance costs, that are incurred on a yearly basis, $d$ is the discount rate and $t$ is the time in years. The capital costs to the plant are only considered in the first year.

Present value of benefits is estimated by Equations 4 or 5, depending upon whether the USFS Subsidy is included

$$
\text { Without subsidy: } \quad B_{P V}=\frac{B_{F}}{(1+d)^{t}}
$$




$$
\text { With subsidy: } \quad B_{P V}=\frac{B_{F}+B_{S}}{(1+d)^{t}}
$$

where $B_{P V}$ is the net present value of total benefits, $B_{F}$ is the fuel cost savings and $B_{S}$ is the value of the USFS subsidy.

Additional electricity cost to consumers (COE) and percent cost increase are considered for the five plants considered with no subsidy. The COE was calculated using Equation 6 (Poonpun et al., 2008).

$$
C O E=\frac{A C C+A O C}{A E P}
$$

Where ACC is the annualized capital costs, AOC is the discounted annual operating costs and AEP is the annual energy production of the plant. Total capital costs (TCC) were annualized using an interest rate of $4 \%$ and the formula given in Equation 7.

$$
A C C=T C C * \frac{i_{r}\left(i_{r}+1\right)^{y}}{\left(1+i_{r}\right)^{y-1}}
$$

Annual energy production for the plant was calculated assuming plants operated at $100 \%$ capacity for the duration of a year. Percent increase over existing electricity costs were calculated using EIA data from April 2016 for consumer electricity prices in Wyoming and Colorado (EIA, 2016).

\section{Results and Discussion}

\subsection{Beetle Kill Biomass Availability}

The heterogeneous biomass distribution as a function of radius was determined for each of the five plants under consideration. Figure 1 shows the 
beetle kill available to each plant as a function of distance from the plant, and the variation in biomass distribution between the five plants can be seen.

Figure 1. Beetle kill available as a function of distance to plant for each of the five plants considered

Rawhide and Cherokee have significantly higher levels of total available beetle kill biomass than the other three plants considered. Rawhide has nearly $80 \%$ of its available biomass within $100 \mathrm{~km}$. FMC and General Chemical, Rawhide and Cherokee have negligible biomass available within $80 \mathrm{~km}, 30 \mathrm{~km}$ and $50 \mathrm{~km}$ respectively. In contrast, Arapahoe has significant biomass available within $16 \mathrm{~km}$ of the plant. These biomass distributions for each plant were used in the economic model to determine accurate transportation distances and associated transportation costs needed to meet the plants' biomass demands.

Figure 2 shows the beetle kill biomass available to each plant normalized based upon each plant's operating capacity, which allows for direct comparison of the biomass availability between plants because plant size determines how much biomass will be needed for co-firing at a given co-firing level.

Figure 2. Normalized beetle kill available based on size of plant (MW) as a function of distance to plant

When normalized, it is apparent that Arapahoe, Cherokee, Martin Drake and Rawhide have comparable amount of beetle kill biomass available relative to their plant sizes. FMC and General Chemical, despite having a relatively low total amount of biomass, as shown in Figure 1, has a significant excess shown in Figure 2 as a result of the small plant size. 
The biomass utilized by co-firing plants removes the beetle kill wood from the forest, thereby contributing to the USFS goal of reducing beetle kill infected areas. Figure 3 shows the fraction of beetle kill biomass in Colorado and Wyoming that would be used if each co-firing scenario was implemented. 'State' results show the fraction of all beetle kill in the entire state utilized in the co-firing scenarios, while 'plant' results show the fraction of beetle kill within the specified $160 \mathrm{~km}$ radius of the plants that would be utilized if Scenario 2 was implemented. Plant results for Scenario 1 are not shown because, by the definition of Scenario 1, the fraction used is $100 \%$.

Figure 3. Fraction of available beetle kill biomass used in Colorado and Wyoming under both scenarios.

Figure 3 shows that Colorado has the potential to utilize a significant fraction of available beetle kill through co-firing while Wyoming does not. Under Scenario 2, Colorado uses nearly $80 \%$ of the beetle kill biomass within the $160 \mathrm{~km}$ range whereas Wyoming only uses $30 \%$ of the available biomass. Colorado is able to effectively treat $20 \%$ and $15 \%$ of total beetle kill area in the entire state under Scenario 1 and Scenario 2, respectively. Wyoming, on the other hand, is only able to treat $4 \%$ and $1 \%$ respectively. A main reason for this difference is that Colorado has four large plants that are capable of co-firing while Wyoming has only one small plant (FMC and General Chemical).

\subsection{Economic Model}

\subsection{1. $\mathrm{CO}_{2}$ Mitigation}


Tables 3 and 4 show the economic model results in terms of $\mathrm{CO}_{2}$ mitigation for Scenario 1 and Scenario 2 respectively. The carbon mitigation costs are average present value costs over 20 years for Scenario 1 and over the operating years possible for Scenario 2. For those plants (Arapahoe, Rawhide and FMC and General Chemical) whose operating years possible under Scenario 2 exceeded 20 years, the operating time was capped at 20 years for economic analysis. Under Scenario 1, the co-firing level determined so that all biomass available within the $160 \mathrm{~km}$ radius of the plant is used within 20 years is given, along with $\mathrm{CO}_{2}$ emission reductions and associated $\mathrm{CO}_{2}$ mitigation costs. Under Scenario 2, the years possible to co-fire at a fixed $20 \%$ co-firing level given the determined beetle kill biomass availability is given, along with $\mathrm{CO}_{2}$ emission reductions and associated $\mathrm{CO}_{2}$ mitigation costs.

Table 3. Economic model results for Scenario 1

Table 4. Economic model results for Scenario 2

As shown in Table 3, the majority of plants operate within or near the range of co-firing levels $(\leq 20 \%)$ currently considered technically feasible for existing plants. Arapahoe and FMC and General Chemical exceed these limits with required co-firing levels of $40.2 \%$ and $67.1 \%$ respectively. As a result, the costs given for these plants may be underestimates of the true costs since their co-firing levels significantly exceed the $20 \%$ viability level at which the costs for the economic model are determined; results are presented in the context that continual advances in co-firing technology and approaches leave open the possibility of achieving these elevated co-firing levels with minimal additional cost in the future. These elevated co-firing limits support the need for improvements to co-firing technology in order 
to increase maximum permissible co-firing levels, and such investments may be deemed worthwhile based on economics of alternative emissions reduction strategies. The $\mathrm{CO}_{2}$ cost for all five plants under Scenario 1 range from $9.34 \$(\mathrm{Mg})^{-1}$ to $11.34 \$(\mathrm{Mg})^{-1}$.

As a result of a wide variation in plant size and biomass availability, the years possible to co-fire under Scenario 2 vary significantly, as shown in Table 4. There is also a much larger variation in $\mathrm{CO}_{2}$ mitigation cost for Scenario 2 compared to Scenario 1. These costs range from $8.34 \$(\mathrm{Mg})^{-1}$ to $15.93 \$(\mathrm{Mg})^{-1}$.

Figure 4 shows the individual plant $\mathrm{CO}_{2}$ emission reductions for Scenario 1 and Scenario 2. These results show that there is significant variation between the two scenarios considered at each plant and also between the five plants themselves. Cherokee is able to reduce $\mathrm{CO}_{2}$ emissions the most of all plants considered for both scenarios, while FMC and General Chemical is able to reduce $\mathrm{CO}_{2}$ the least.

Figure 4. Individual plant annual $\mathrm{CO}_{2}$ emission reductions for Scenario 1 and Scenario 2

Another important consideration is how the possible $\mathrm{CO}_{2}$ emission reductions relate to the requirements of $\mathrm{CO}_{2}$ reduction policies, in this case specifically the EPA Clean Power Plan. The required emission reductions were determined by taking the total $\mathrm{CO}_{2}$ emissions for the state and reducing that by the amount needed to achieve the required emission reduction fractions of the CPP for each state. The possible emission reductions for each state achieved by co-firing were determined by adding all of the $\mathrm{CO}_{2}$ emissions, as given in Tables 3 and 4 , for the plants in each state. 
For Wyoming, the fraction of emission reduction requirements met were 0.3 $\%$ and $1.0 \%$ for Scenario 1 and Scenario 2 respectively. Given that the only plant considered in Wyoming is FMC and General Chemical, all of the possible emission reductions for Wyoming came from this single plant. Since this is also a relatively small plant in terms of operating capacity, the total possible emission reductions were very small, leading to an insignificant fraction of required emission reductions met by co-firing for Wyoming. Colorado is able to meet more of the required emission reductions, with the fraction met being $13.5 \%$ and $15.2 \%$ for Scenario 1 and Scenario 2 respectively. These results suggest that co-firing with beetle kill biomass may be a viable option to meet part of the EPA Clean Power Plan requirements for Colorado, but not for Wyoming.

\subsubsection{Cumulative Costs}

Figures 5 and 6 show the cumulative additional costs to each of the five plants for Scenario 1 and Scenario 2 respectively. These costs represent accumulative total additional cost to the plant over the years of operation possible at this co-firing rate, given biomass availability. Costs are presented in present value dollars. Costs for each case are presented without the USFS subsidy.

Figure 5. Scenario 1 discounted cumulative costs without subsidy

Figure 6. Scenario 2 discounted cumulative costs without subsidy

Figure 7 shows the additional cost to the consumer in $\$ \mathrm{kWh}^{-1}$ and percent increase for each of the five plants considered and both scenarios. FMC and General Chemical has the highest additional cost for Scenario 1 at $0.0098 \$ \mathrm{kWh}^{-1}$ while Martin Drake has the lowest at $0.0010 \$ \mathrm{kWh}^{-1}$. Generally speaking, costs for 
Scenario 1 are higher than Scenario 2, with the exception of Cherokee and Martin Drake. There is much less variation between the costs for Scenario 2 than Scenario 1.

Figure 7. Additional cost to consumer and percent increase for Scenario 1 and Scenario 2 for individual plants.

Based on the most recent data available from the EIA for April 2016, the average residential cost of electricity was .1178 $\$ \mathrm{kWh}^{-1}$ and $.1099 \$ \mathrm{kWh}^{-1}$ in Colorado and Wyoming respectively. As shown in Figure 7, percent increase in cost of electricity ranges between $1 \%$ to $9 \%$ across the five plants considered and both scenarios.

\subsubsection{USFS Subsidy}

Figure 8 shows the costs of $\mathrm{CO}_{2}$ mitigation per $\mathrm{Mg}$ of $\mathrm{CO}_{2}$ reduced to each plant for both scenarios considered with and without the USFS subsidy. As shown, there is very little variation in this cost for all five plants in Scenario 1 without the subsidy. Costs range from $9.34 \$ \mathrm{Mg}^{-1}$ to $11.34 \$ \mathrm{Mg}^{-1}$ for this scenario. Given the wide variation in plant size and beetle kill availability, it is interesting that the cost of $\mathrm{CO}_{2}$ mitigation is so similar for all five plants. This result suggests that even with varying circumstances, co-firing with beetle kill biomass will be nearly the same cost across a wide array of plants.

Figure 8. $\mathrm{CO}_{2}$ mitigation costs for both of the scenarios considered with and without the USFS Subsidy for the five plants considered

There is a wider range of costs for Scenario 2, which likely results in part from the fact that in Scenario 2, the plants are operating for varying time periods, 
affecting the average $\mathrm{CO}_{2}$ cost. As shown, the inclusion of the subsidy significantly decreases the overall cost. In some cases, the cost to the plant is negative, indicating a financial gain to the plant with the inclusion of the subsidy. This means that in order for plants to break even with co-firing, any additional subsidy could be less than the value of the USFS subsidy used in this study.

\subsubsection{Cost Comparisons}

The $\mathrm{CO}_{2}$ costs determined by this study can be compared to other carbon reduction technologies to determine the advantage that co-firing might have over other strategies for meeting EPA CPP requirements. For example, the anticipated cost of carbon capture and storage (CCS) technology is between $25 \$ \mathrm{Mg}^{-1}$ to $101 \$$ $\mathrm{Mg}^{-1}$ for $\mathrm{CO}_{2}$ sequestration (Abellera et al., 2011). Additionally, global carbon tax rates vary between $2 \$ \mathrm{Mg}^{-1}$ and $154 \$ \mathrm{Mg}^{-1}$ on $\mathrm{CO}_{2}$ emitted (World Bank, 2014). Biomass co-firing, as considered by the present study, is shown to be an attractive option with average $\mathrm{CO}_{2}$ costs of approximately $5 \$\left(\mathrm{Mg} \mathrm{CO}_{2}\right)^{-1}$ (based upon averaging the $\mathrm{CO}_{2}$ costs for all cases and scenarios considered) significantly lower than most other low-carbon technologies and comparable to other low-carbon technologies such as onshore wind. For existing power plants, another option available to decrease emissions while continuing operation is carbon capture and storage. CCS technology is currently significantly more expensive than co-firing. Furthermore, CCS technology is not yet commercially mature (Abellera et al., 2011). In addition to co-firing and CCS implementation, existing plants could try to achieve carbon emission reductions through heat rate improvements, but these are also expensive and hold little promise for significant $\mathrm{CO}_{2}$ reduction; efficiency 
improvements have already been widely implemented in many power plants, meaning further improvements will come as diminishing returns on significant investments. This comparison demonstrates the financial attractiveness of biomass co-firing as a carbon reduction strategy for existing coal fired power plants. The current study limits the transportation distance to $160 \mathrm{~km}$, however, the low cost of co-firing compared to other technologies could allow for an increase in transportation costs while still being an economically competitive option. This expands the radius for beetle kill biomass harvest around plants, which would effectively increase the number of existing plants that would be viable for co-firing and increase the amount of biomass available for co-firing.

\subsection{Other Considerations}

For the purposes of this study, it was assumed that beetle kill biomass found in National Forests was available for harvest and utilization in co-firing applications dependent simply on cost and biomass availability. It is important to note that, in actuality, there would need to be extensive formal planning and the agreement of governing agencies in order to use the available beetle kill wood in the manner

proposed in this study. Forest plans and land management and resource use documents govern the activities that take place on National Forest lands. These documents are required under the Forest and Rangeland Renewable Resources Planning Act of 1974 and the National Forest Management Act (Forest and Rangeland Renewable Resources Planning Act of 1974, 1974; National Forest Management Act of 1976, 1976). Use or extraction of any National Forest resources must be specifically included in these plans before action can be taken. For the 
beetle kill biomass harvest and utilization discussed in this study to be implemented, existing forest plans would need to be changed.

\section{Conclusion and Policy Implications}

This study explored the biomass availability, economic feasibility and potential $\mathrm{CO}_{2}$ emission reductions of co-firing beetle kill biomass with coal in existing coal fired power plants, and the economic impact of an additional novel subsidy based upon USFS beetle kill treatment costs. There are five existing coal fired power plants in Colorado and Wyoming that are viable candidates for co-firing with beetle kill biomass; these plants are in close proximity to National Forests with significant tree mortality to provide the required fuel density for co-firing. Two scenarios were considered for all three states. Scenario 1 determined the co-firing level needed to utilize all available beetle kill biomass within $160 \mathrm{~km}$ of each plant in 20 years. Co-firing levels ranged from $6 \%$ to $67 \%$, dependent upon varying plant size and beetle kill biomass availability. Scenario 2 fixed the co-firing level at $20 \%$ and determined the co-firing years possible. The cost for $\mathrm{CO}_{2}$ mitigation for all five plants under both scenarios was determined both with and without the inclusion of the USFS subsidy. The inclusion of this subsidy to incentivize co-firing based upon USFS funding to manage beetle kill was found to significantly decrease the cost per $\mathrm{Mg}$ of $\mathrm{CO}_{2}$ mitigated. This cost is significantly lower than most other currently available alternative carbon reduction technologies; thus, the results indicate that co-firing of biomass with coal is a near term and viable option for carbon emissions reduction in power plants.

\section{Acknowledgements}


This material is based upon work supported by the National Science Foundation

Graduate Research Fellowship under Grant No. 12-52375. Special thanks to Dr.

Steve Smutko of the University of Wyoming Haub School of Environment and

Natural Resources for providing helpful insights and comments on this study.

\section{References}

Abellera, Chester, and Christopher Short. 2011. "The Costs of CCS and Other LowCarbon Technologies." Global CCS Institute. http://hub.globalccsinstitute.com/sites/default/files/publications/24202/c osts-ccs-and-other-low-carbon-technologies.pdf.

Baxter, Larry. 2005. "Biomass Coal Co-Combustion: Opportunity for Affordable Renewable Energy." Fuel 84: 1295-1302.

Climate Change Division. 2014. "Framework for Assessing Biogenic CO2 Emissions from Stationary Sources." Washington D.C.: United States Environmental Protection Agency. http://www3.epa.gov/climatechange/downloads/Framework-forAssessing-Biogenic-CO2-Emissions.pdf.

EIA. 2016. "Electric Power Monthly with Data for April 2016." Energy Information Administration.

EPA. 2015a. "Carbon Pollution Emission Guidelines for Existing Stationary Sources: Electric Utility Generating Units." Awaiting publication in Federal Register. Environmental Protection Agency. http://www2.epa.gov/sites/production/files/2015-08/documents/cppfinal-rule.pdf.

- - - 2015b. "Clean Power Plan: State at a Glance Colorado." Environmental Protection Agency. http://www3.epa.gov/airquality/cpptoolbox/colorado.pdf\#_ga=1.20153358 5.1205876227.1445571937.

_- - 2015c. "Clean Power Plan: State at a Glance Wyoming." Environmental Protection Agency. http://www3.epa.gov/airquality/cpptoolbox/wyoming.pdf\#_ga=1.2314254 39.1205876227.1445571937.

- - - 2015d. "Components of the Clean Power Plan: Setting States Goals to Cut Carbon Pollution." Fact Sheet. EPA Clean Power Plan. Environmental Protection Agency.

Eriksson, Ola, Göran Finnveden, Tomas Ekvall, and Anna Björklund. 2007. "Life Cycle Assessment of Fuels for District Heating: A Comparison of Waste Incineration, Biomass-and Natural Gas Combustion." Energy Policy 35 (2): 1346-1362. 
Escudero, Marcos, Ángel Jiménez, Celina González, and Ignacio López. 2013. "Quantitative Analysis of Potential Power Production and Environmental Benefits of Biomass Integrated Gasification Combined Cycles in the European Union." Energy Policy 53: 63-75.

Forest and Rangeland Renewable Resources Planning Act of 1974. 1974.

Galik, Christopher S, Robert C Abt, Gregory Latta, and Tibor Vegh. 2015. “The Environmental and Economic Effects of Regional Bioenergy Policy in the Southeastern US." Energy Policy 85: 335-346.

Gan, Jianbang, and CT Smith. 2006. "A Comparative Analysis of Woody Biomass and Coal for Electricity Generation under Various CO 2 Emission Reductions and Taxes." Biomass and Bioenergy 30 (4): 296-303.

Goerndt, Michael E, Francisco X Aguilar, and Kenneth Skog. 2013. "Resource Potential for Renewable Energy Generation from Co-Firing of Woody Biomass with Coal in the Northern US." Biomass and Bioenergy 59: 348-361.

Governor Mead, Matt. 2013. "Leading the Charge: Wyoming's Action Plan for Energy, Environment and Economy." Cheyenne, WY. http://issuu.com/energy_strategy/docs/wy_energy_strategy?e=8164076/26 18210.

Hansson, Julia, Göran Berndes, Filip Johnsson, and Jan Kjärstad. 2009. “Co-Firing Biomass with Coal for Electricity generation-An Assessment of the Potential in EU27." Energy Policy 37 (4): 1444-1455.

Hein, KRG, and JM Bemtgen. 1998. "EU Clean Coal Technology - Co-Combustion of Coal and Biomass." Fuel Processing Technology 54 (1): 159-69.

Hughes, Evan. 2000. "Biomass Cofiring: Economics, Policy and Opportunities." Biomass and Bioenergy 19: 457-65.

Jeffers, Robert F, Jacob J Jacobson, and Erin M Searcy. 2013. "Dynamic Analysis of Policy Drivers for Bioenergy Commodity Markets." Energy Policy 52: 249263.

Jenkins, Michael J, Elizabeth Hebertson, Wesley Page, and C Arik Jorgensen. 2008. "Bark Beetles, Fuels, Fires and Implications for Forest Management in the Intermountain West." Forest Ecology and Management 254 (1): 16-34.

John T. Boyd Company. 2011. "Powder River Basin Coal Resource and Cost Study." 3155.001. Denver, Colorado: Mining and Geological Consultants.

Kayhanian, Massoud, George Tchobanoglous, and Robert Brown. 2007. "Biomass Conversion Processes For Energy Recovery." In Handbook of Energy Efficiency and Renewable Energy, edited by Frank Kreith and DY Goswami, 25-37-25-50. Boca Raton, FL: CRC Press.

Liu, Zuoming, Ira Altman, and Thomas Johnson. 2014. "The Feasibility of Co-Firing Biomass for Electricity in Missouri." Biomass and Bioenergy 69: 12-20.

Meddens, Arjan JH, and Jeffrey A Hicke. 2014. "Spatial and Temporal Patterns of Landsat-Based Detection of Tree Mortality Caused by a Mountain Pine Beetle Outbreak in Colorado, USA." Forest Ecology and Management 322: 78-88.

Meigs, Garrett W, Harold SJ Zald, John L Campbell, William S Keeton, and Robert E Kennedy. 2016. "Do Insect Outbreaks Reduce the Severity of Subsequent Forest Fires?" Environmental Research Letters 11 (4): 45008. 
Mobini, Mahdi, Taraneh Sowlati, and Shahab Sokhansanj. 2011. "Forest Biomass Supply Logistics for a Power Plant Using the Discrete-Event Simulation Approach." Applied Energy 88 (4): 1241-1250.

Moore, Mark A, Anthony E Boardman, Aidan R Vining, David L Weimer, and David H Greenberg. 2004. 'Just Give Me a Number!' Practical Values for the Social Discount Rate." Journal of Policy Analysis and Management 23 (4): 789-812. National Forest Management Act of 1976. 1976.

Poonpun, Piyasak, Ward T Jewell, and others. 2008. "Analysis of the Cost per Kilowatt Hour to Store Electricity." IEEE Transactions on Energy Conversion 23 (2): 529-534.

Prestemon, Jeffrey, Karen Abt, Kevin Potter, and Frank Koch. 2013. "An Economic Assessment of Mountain Pine Beetle Timber Salvage in the West." Western Journal of Applied Forestry 28 (4): 143-53.

Rasband, W.S. ImageJ, U. S. National Institutes of Health, Bethesda, Maryland, USA, http://imagej.nih.gov/ij/ 1997-2014.

Reijnders, L. 2006. “Conditions for the Sustainability of Biomass Based Fuel Use." Energy Policy 34 (7): 863-76. doi:http://dx.doi.org/10.1016/j.enpol.2004.09.001.

Row, Clark, H Fred Kaiser, and John Sessions. 1981. "Discount Rate for Long-Term Forest Service Investments." Journal of Forestry 79 (6): 367-376.

Sahu, SG, N Chakraborty, and P Sarkar. 2014. "Coal-biomass Co-Combustion: An Overview." Renewable and Sustainable Energy Reviews 39: 575-586.

Sami, M, K Annamalai, and M Wooldridge. 2001. "Co-Firing of Coal and Biomass Fuel Blends." Progress in Energy and Combustion Science 27 (2): 171-214.

Tharakan, Pradeep J, Timothy A Volk, Christopher A Lindsey, Lawrence P Abrahamson, and Edwin $\mathrm{H}$ White. 2005. "Evaluating the Impact of Three Incentive Programs on the Economics of Cofiring Willow Biomass with Coal in New York State." Energy Policy 33 (3): 337-347.

U.S. Forest Service. 2011a. "U.S. Forest Service Insect and Disease Survey - Western Bark Beetle." ArcGIS Map Server. U.S. Forest Service. http://apps.fs.fed.us/arcx/rest/services/EDW/EDW_IDSurveyWesternBark Beetles_01/MapServer.

——_. 2011b. "Western Bark Beetle Strategy: Human Safety, Recovery and Resiliency." USDA. http://www.fs.fed.us/publications/bark-beetle/barkbeetle-strategy-appendices.pdf.

——_. 2014. "Requests for Proposals: 2014 Statewide Wood Energy Teams Cooperative Agreement; and 2014 Wood to Energy Grant." Federal Register, April. https://federalregister.gov/a/2014-08778.

Wilkerson, Jordan, Peter Larsen, and Galen Barbose. 2014. "Survey of Western US Electric Utility Resource Plans." Energy Policy 66: 90-103.

World Bank. 2014. "Putting a Price on Carbon with a Tax." http://www.worldbank.org/content/dam/Worldbank/document/SDN/back ground-note_carbon-tax.pdf. 


\section{Highlights}

- Beetle kill biomass availability for co-firing in WY and CO assessed via GIS

- Economics of co-firing with beetle kill biomass in power plants presented

- Novel policy to use Forest Service funding to subsidize co-firing considered

- A portion of EPA Clean Power Plan requirements can be met through biomass cofiring

- Co-firing among the most economical ways to meet emission reduction requirements 


\begin{tabular}{|l|c|r|}
\hline \multicolumn{1}{|c|}{ Plant } & State & \multicolumn{1}{c|}{$\begin{array}{c}\text { Capacity } \\
\text { (MW) }\end{array}$} \\
\hline Arapahoe & CO & 152.5 \\
\hline Cherokee & CO & 551.3 \\
\hline Martin Drake & CO & 257.0 \\
\hline Rawhide & CO & 293.6 \\
\hline FMC and General Chemical & WY & 35.0 \\
\hline
\end{tabular}

Table 1. Selected plant characteristics

\begin{tabular}{|c|c|c|}
\hline Data Type & Value & Source \\
\hline Capital & $50 \$ \mathrm{~kW}^{-1}$ to & (Hughes, 2000) \\
\hline Operation \& maintenance & $100 \$ \mathrm{~kW}^{-1}$ & (Liu et al., 2014) \\
\hline Transportation (Fixed) & $7.50 \$ \mathrm{~kW}^{-1}$ & (Goerndt et al., 2013) \\
\hline Transportation (Variable) & $0.15 \$ \mathrm{Mg}^{-1} \mathrm{~km}^{-1}$ & (Goerndt et al., 2013) \\
\hline Harvesting & $16.04 \$ \mathrm{Mg}^{-1}$ & (Goerndt et al., 2013) \\
\hline Chipping & $5.51 \$ \mathrm{Mg}^{-1}$ & (Goerndt et al., 2013) \\
\hline Forest Service Region 2 funds & $33 \mathrm{M} \$^{-1}$ & (U.S. Forest Service, 2011b) \\
\hline Region 2 area to be treated & $151 \mathrm{~km}^{2}$ & (U.S. Forest Service, 2011b) \\
\hline Discount Rate & $4 \%$ & (Row, 1981; Moore, 2004) \\
\hline
\end{tabular}

Table 2. Summary of economic model input values 


\begin{tabular}{|c|c|c|c|}
\hline Plant & $\begin{array}{l}\text { Co-firing Percent } \\
\text { (\% energy) }\end{array}$ & $\begin{array}{c}\mathrm{CO}_{2} \text { Emission Reductions } \\
{\left[\mathrm{Mg} \mathrm{yr}^{-1}\right]}\end{array}$ & $\begin{array}{c}\mathrm{CO}_{2} \mathrm{Cost}_{\left[\mathrm{CO}_{2}\right)^{-1]}(\mathrm{Mg}} \\
\end{array}$ \\
\hline Arapahoe & $40.2 \%$ & 772,669 & 11.03 \\
\hline Cherokee & $13.1 \%$ & 948,223 & 11.34 \\
\hline Martin Drake & $6.4 \%$ & 230,626 & 9.34 \\
\hline Rawhide & $24.1 \%$ & 903,984 & 11.28 \\
\hline $\begin{array}{l}\text { FMC and General } \\
\text { Chemical }\end{array}$ & $67.1 \%$ & 293,793 & 9.69 \\
\hline
\end{tabular}

Table 3. Economic model results for Scenario 1

\begin{tabular}{|c|c|c|c|}
\hline Plant & $\begin{array}{c}\text { Co-firing Years } \\
\text { Possible }\end{array}$ & $\begin{array}{c}\mathrm{CO}_{2} \text { Emission Reductions } \\
{\left[\mathrm{Mg} \mathrm{yr}^{-1}\right]}\end{array}$ & $\begin{array}{l}\mathrm{CO}_{2} \mathrm{Cost}_{\left.\mathrm{CO}_{2}\right)^{-1]}}^{\text {Cl] }(\mathrm{Mg}} \\
\end{array}$ \\
\hline Arapahoe & 38 & 392,805 & 9.86 \\
\hline Cherokee & 13 & $1,420,024$ & 12.44 \\
\hline Martin Drake & 6 & 661,974 & 15.93 \\
\hline Rawhide & 23 & 756,247 & 8.34 \\
\hline $\begin{array}{l}\text { FMC and General } \\
\text { Chemical }\end{array}$ & 64 & 90,152 & 10.14 \\
\hline
\end{tabular}

Table 4. Economic model results for Scenario 2 


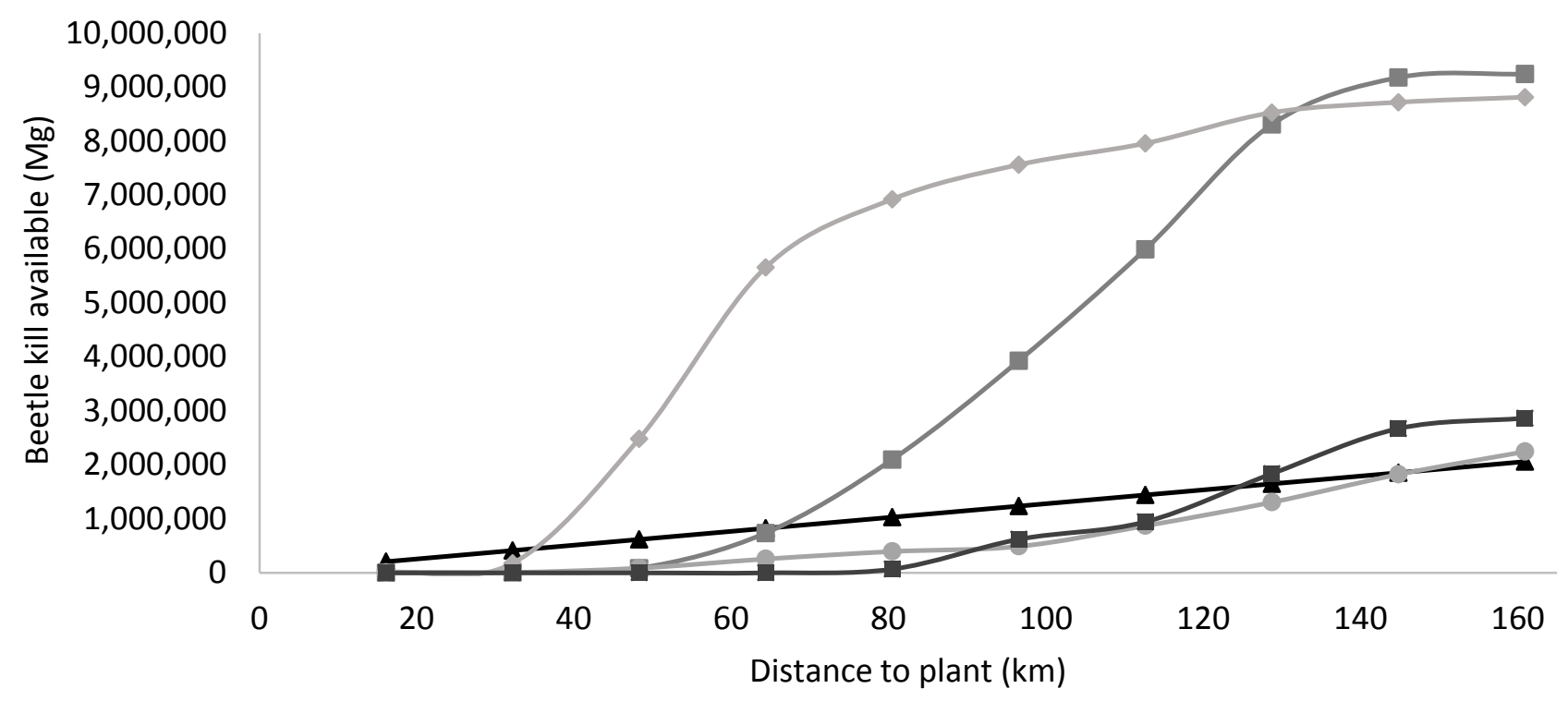

$\rightarrow$ Arapahoe $\rightarrow$ Cherokee $\longrightarrow$ Martin Drake $\multimap$ Rawhide $\rightarrow$ FMC and General Chemical

Figure 1. Beetle kill available as a function of distance to plant for each of the five plants considered

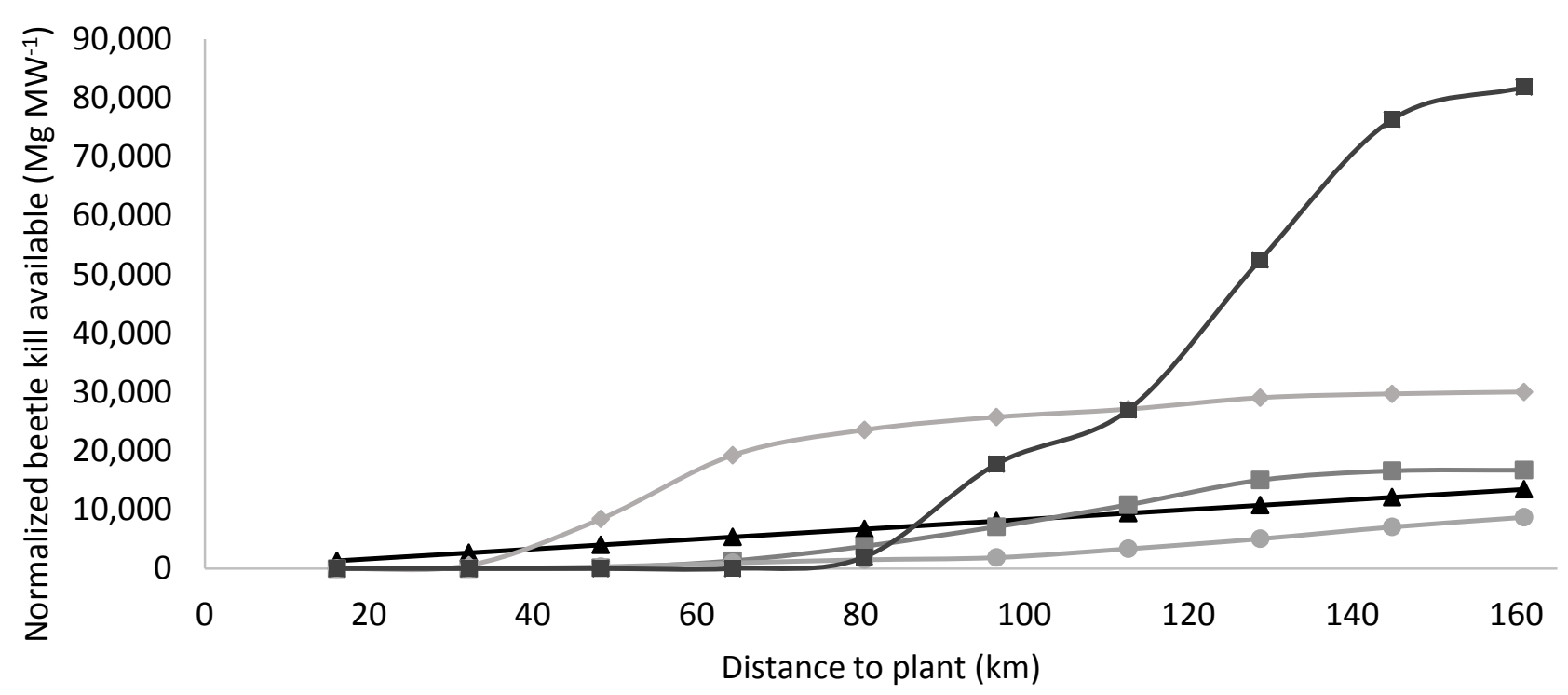

$\rightarrow$ Arapahoe $\rightarrow-$ Cherokee $\rightarrow$ Martin Drake $\rightarrow$ Rawhide $\rightarrow$ FMC and General Chemical

Figure 2. Normalized beetle kill available based on size of plant (MW) as a function of distance to plant 


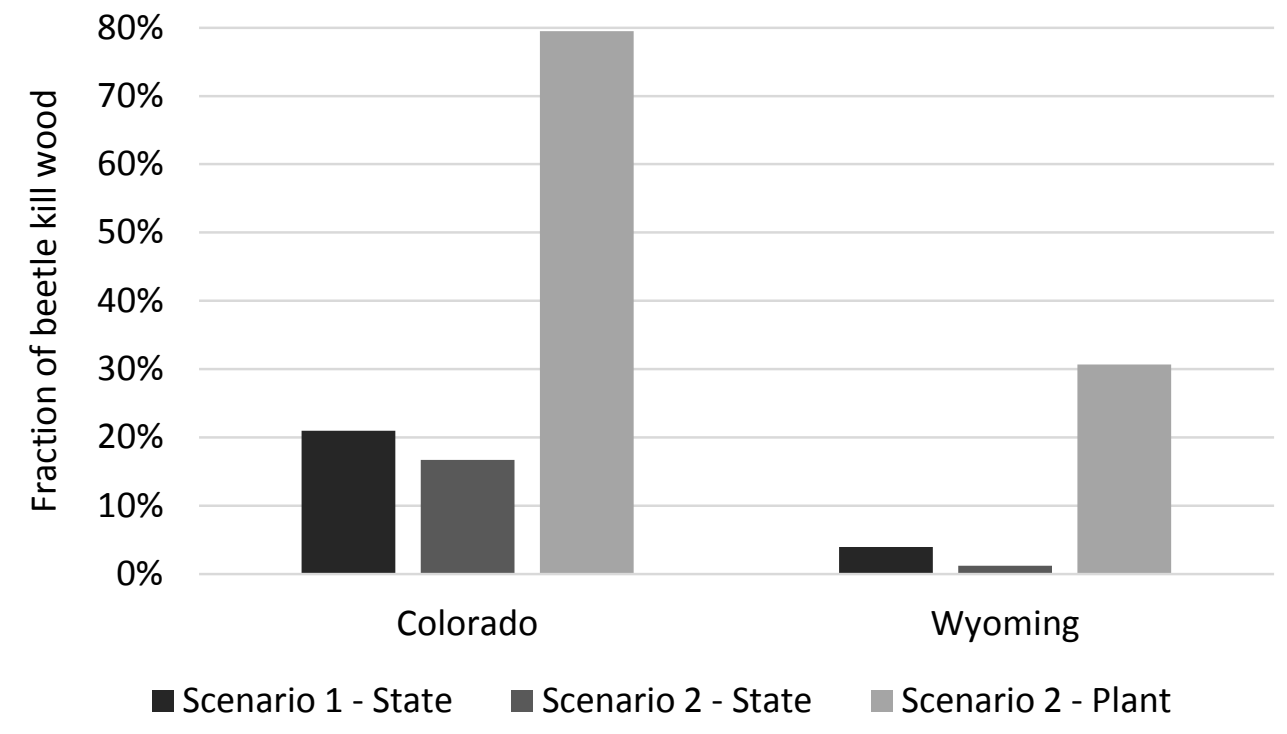

Figure 3. Fraction of available beetle kill biomass used for Colorado and Wyoming in both scenarios 


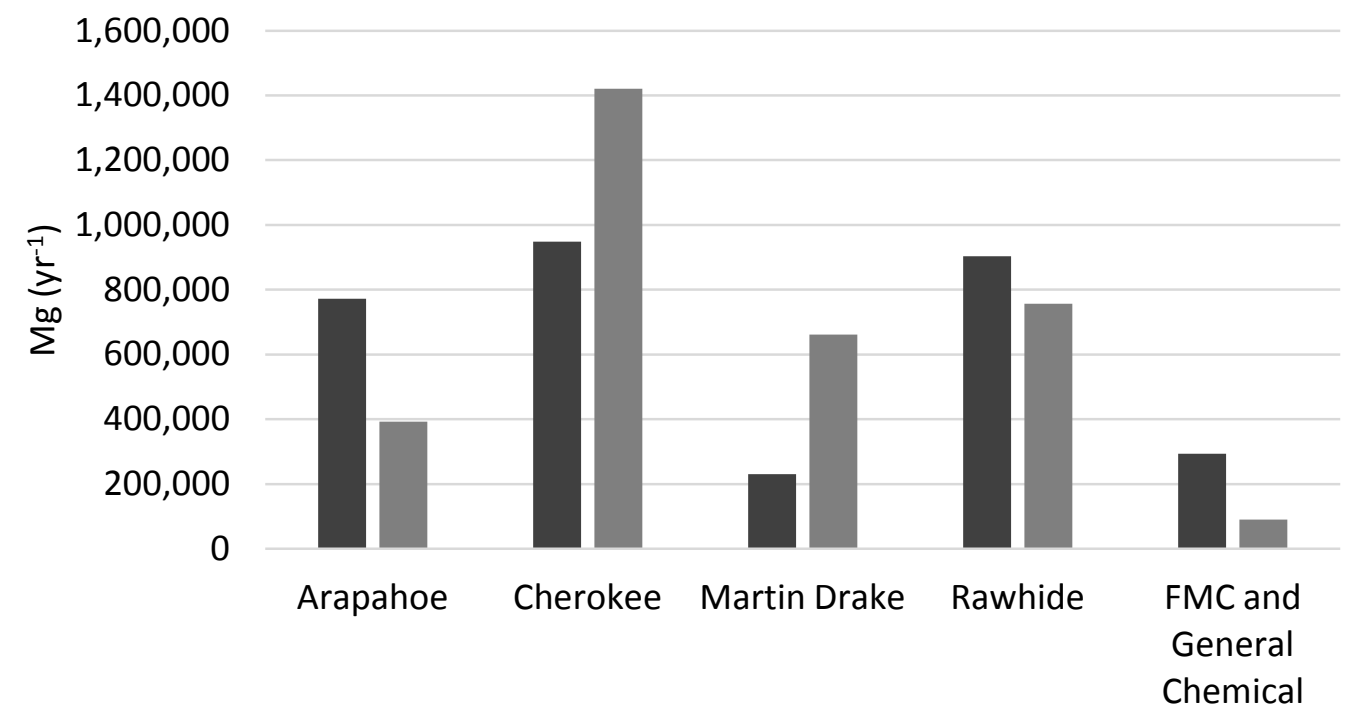

Scenario 1 Scenario 2

Figure 4. Individual plant annual $\mathrm{CO}_{2}$ emission reductions for Scenario 1 and Scenario 2

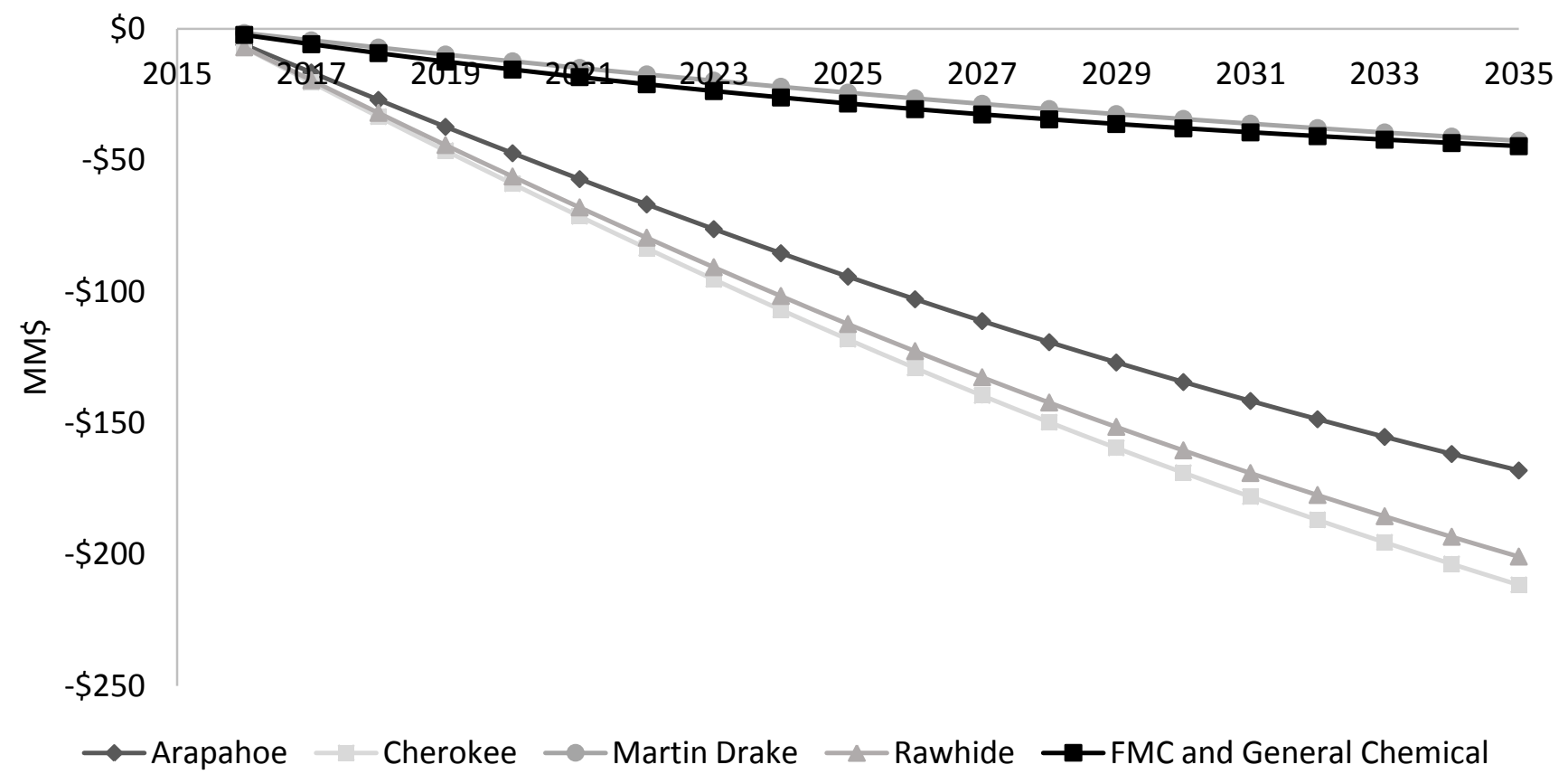

Figure 5. Scenario 1 discounted cumulative costs without subsidy 


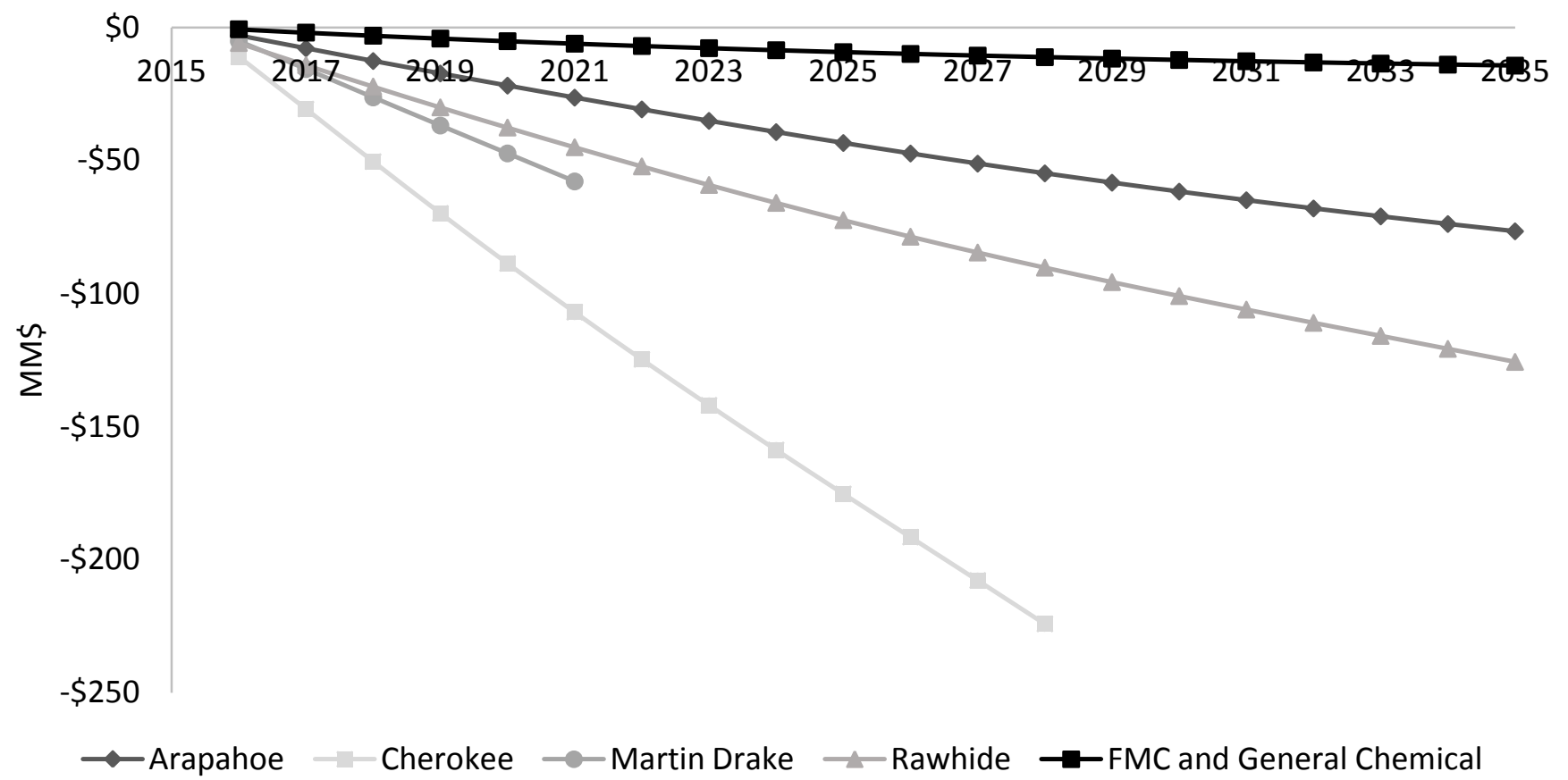

Figure 6. Scenario 2 discounted cumulative costs without subsidy

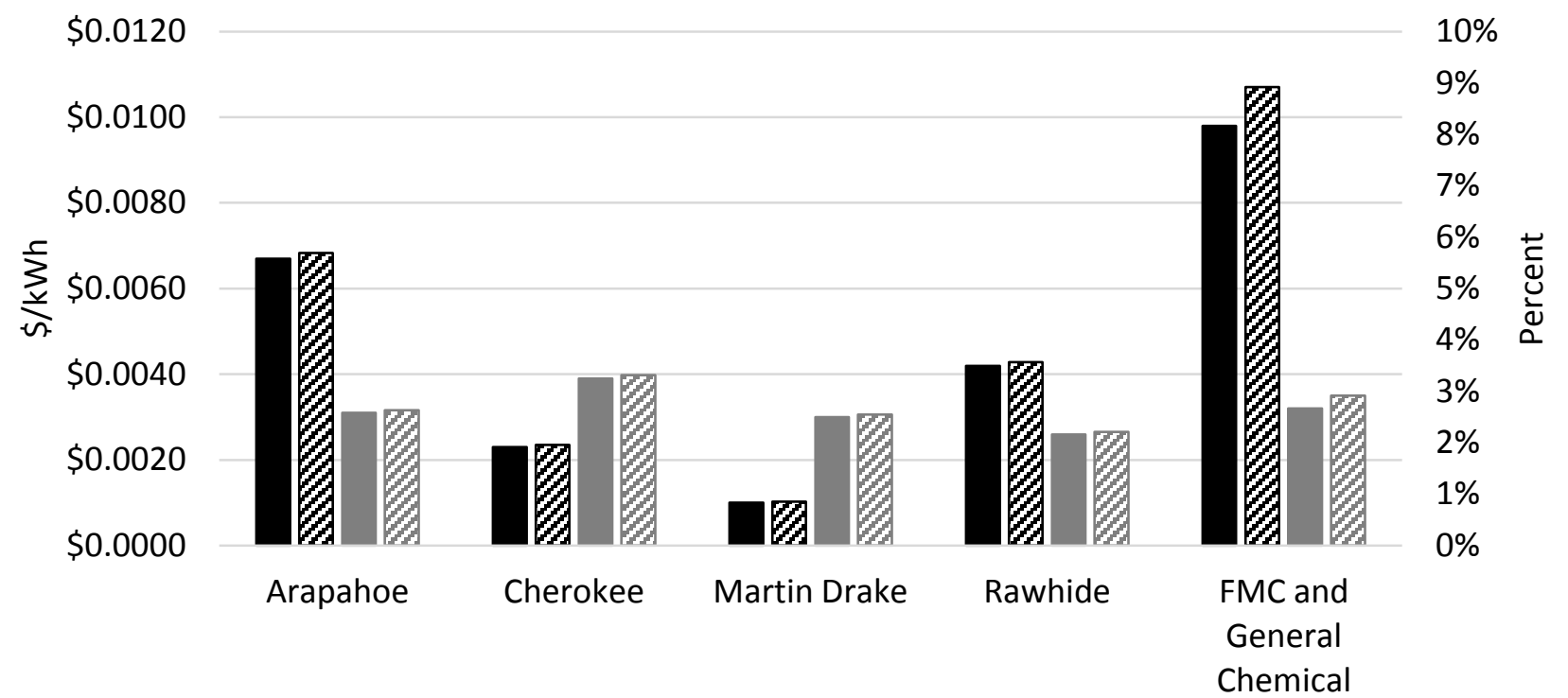

- Scenario 1 - COE $(\$ / \mathrm{kWh})$

Scenario 2 - COE $(\$ / \mathrm{kWh})$

๑ Scenario 1 - \% Increase

$\square$ Scenario 2 - \% Increase

Figure 7. Additional cost to consumer and percent increase for Scenario 1 and Scenario 2 for individual plants 


$\$ 20.00 \quad$ Scenario $1 \quad$ Scenario $1 \mathrm{w} /$ Subsidy Scenario $2 \quad$ Scenario $2 \mathrm{w} /$ Subsidy

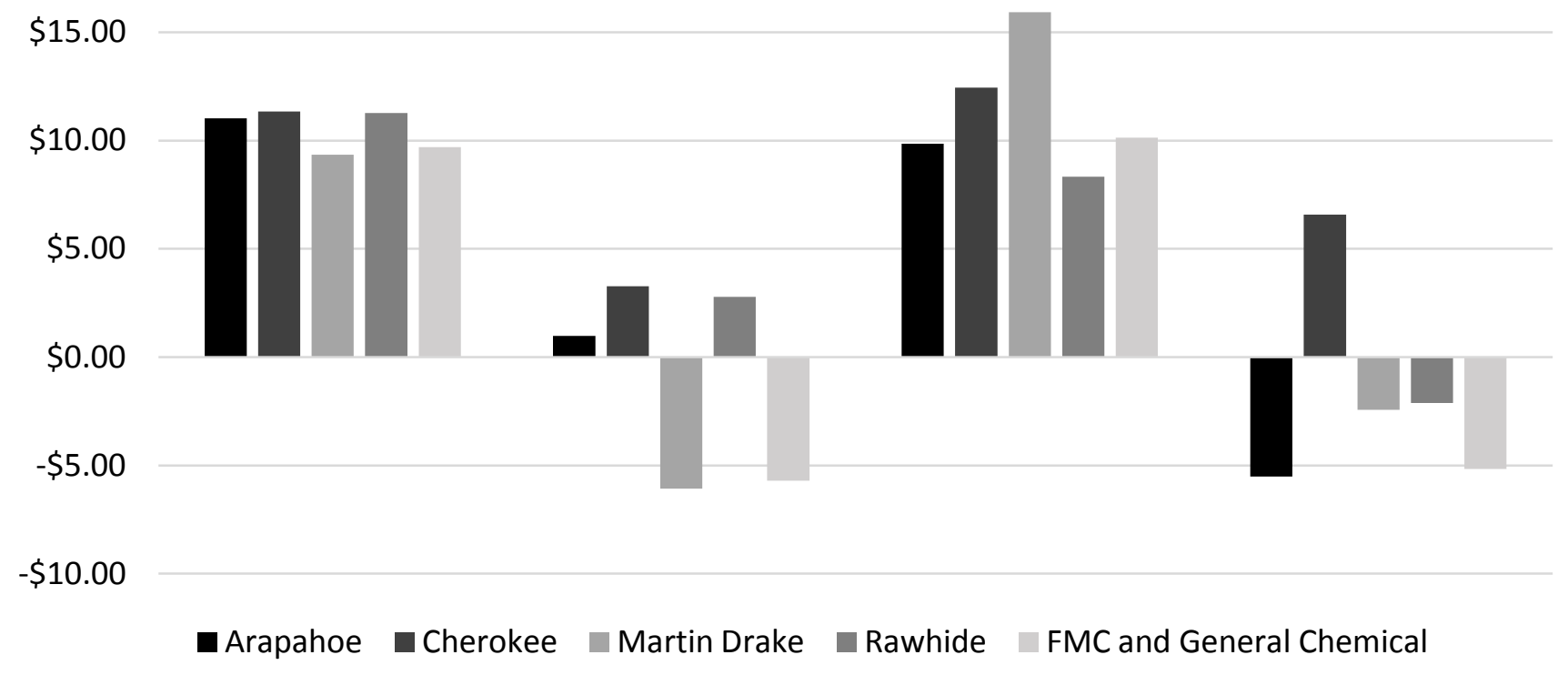

Figure 8. $\mathrm{CO}_{2}$ mitigation costs for both of the scenarios considered with and without the Forest Service subsidy for the five plants considered 